\title{
Experiences during the first four years of a postpartum perineal clinic in the USA
}

\author{
Cynthia Brincat ${ }^{\mathrm{a}}$, Erin Crosby $^{\mathrm{b}}$, Anne McLeod ${ }^{\mathrm{c}}$, Dee E. Fenner ${ }^{\mathrm{b}, *}$ \\ a Division of Female Pelvic Medicine and Reconstructive Surgery, Loyola University, Chicago, IL, USA \\ ${ }^{\mathrm{b}}$ Department of Obstetrics and Gynecology, University of Michigan, Ann Arbor, MI, USA \\ c School of Nursing, University of Michigan, Ann Arbor, MI, USA
}

\section{A R T I C L E I N F O}

\section{Article history:}

Received 18 March 2014

Received in revised form 15 July 2014

Accepted 1 September 2014

\section{Keywords:}

Incontinence

Lacerations

Pelvic floor dysfunction

Postpartum perineal clinic

Vaginal delivery

\begin{abstract}
A B S T R A C T
Objective: To assess the characteristics of patients seen at a postpartum perineal clinic in the USA during the first 4 years of its existence, and to identify factors contributing to the clinic's success. Methods: In a retrospective study, the charts of patients presenting to the clinic between July 1, 2007, and June 30, 2011, were reviewed for presenting complaint, findings, treatment, number of visits, and referral source. Strategies that led to successful clinic implementation were reviewed. Results: A total of 247 patients were seen during the 4-year period. Indications for referral included lacerations, pain, urinary and fecal incontinence, and fistulas. The most common referral indication was a third- or fourth-degree laceration, which affected 154 (62.3\%) patients. Overall, 53 (21.5\%) patients required a procedure, of whom 20 (8.1\%) underwent surgery. Most women were counseled about pelvic floor exercises, and 39 (15.8\%) were referred for pelvic floor physical therapy. Nurse-led triage, patient education, and follow-up were key to the success of the program. Conclusion: The postpartum perineal clinic is sustainable and offers an opportunity for early assessment and treatment of pelvic floor dysfunction after a complicated vaginal delivery.
\end{abstract}

(c) 2014 Published by Elsevier Ireland Ltd. on behalf of International Federation of Gynecology and Obstetrics.

\section{Introduction}

Often a time of great joy and anticipation, the postpartum period is also a stressful time of change for mothers and families. The situation can be compounded by complications of perineal trauma common with vaginal birth, such as fistulas, fecal and urinary incontinence, perineal pain, and wound breakdown. Although there is some knowledge about how birth injuries can progress to pelvic floor dysfunction, little is known about the impact of early treatment for birth-related pelvic floor dysfunction.

At the University of Michigan (UMI; Ann Arbor, MI, USA), increasing numbers of women were being seen for postpartum perineal trauma within the general urogynecology practice, which did not have appropriate resources and protocols for their care. For women who have had a complex vaginal delivery (an operative vaginal delivery), or have perineal or sphincter lacerations or significant pain, routine 6week follow-up may be inadequate. Therefore, on the basis of a European model [1], a postpartum perineal clinic (the Michigan Healthy Healing After Delivery Clinic) was established at the UMI in July 2007.

The clinic was established as a subspecialty referral center, not as a replacement for routine postpartum care. The focus of the clinic has

\footnotetext{
* Corresponding author at: Department of Obstetrics and Gynecology, University of Michigan, L4000 Women's Hospital, 1500 E. Medical Center Dr., Ann Arbor, MI 48109, USA. Tel.: +1 734647 5866; fax: +1 7346479727.

E-mail address: deef@med.umich.edu (D.E. Fenner).
}

been to evaluate patients, educate individuals about their condition, develop a treatment plan, and then return them to the referring provider (Fig. 1). After delivery or when an issue is identified in the postpartum period, patients or their primary obstetric providers call the clinic's central number to arrange assessment. The patient is then triaged by the clinic's nursing staff. Clinic guidelines determine that patients should be seen within 2 weeks of the initial referral and that delivery should have occurred less than 1 year ago. The clinic is staffed by urogynecologists who identify and treat postpartum pelvic floor problems. For each visit, staff attempted to follow a standard procedure, including review of a patient's delivery records, noting the length of the second stage of labor, type of delivery (e.g. spontaneous or assisted), laceration, and method of repair.

The aim of the present study was to assess the clinic and patient profile as well as interventions for women seen in the postpartum perineal clinic during its first 4 years.

\section{Materials and methods}

In a retrospective study, the charts of all patients presenting to the Michigan Healthy Healing After Delivery Clinic between July 1, 2007, and June 30, 2011, were reviewed. The UMI institutional review board approved the chart review. All patient information was de-identified, so patient consent was not required for the chart review.

Data extracted included presenting complaint, findings, treatment, number of visits, and referral source. Likewise, the positive steps taken 


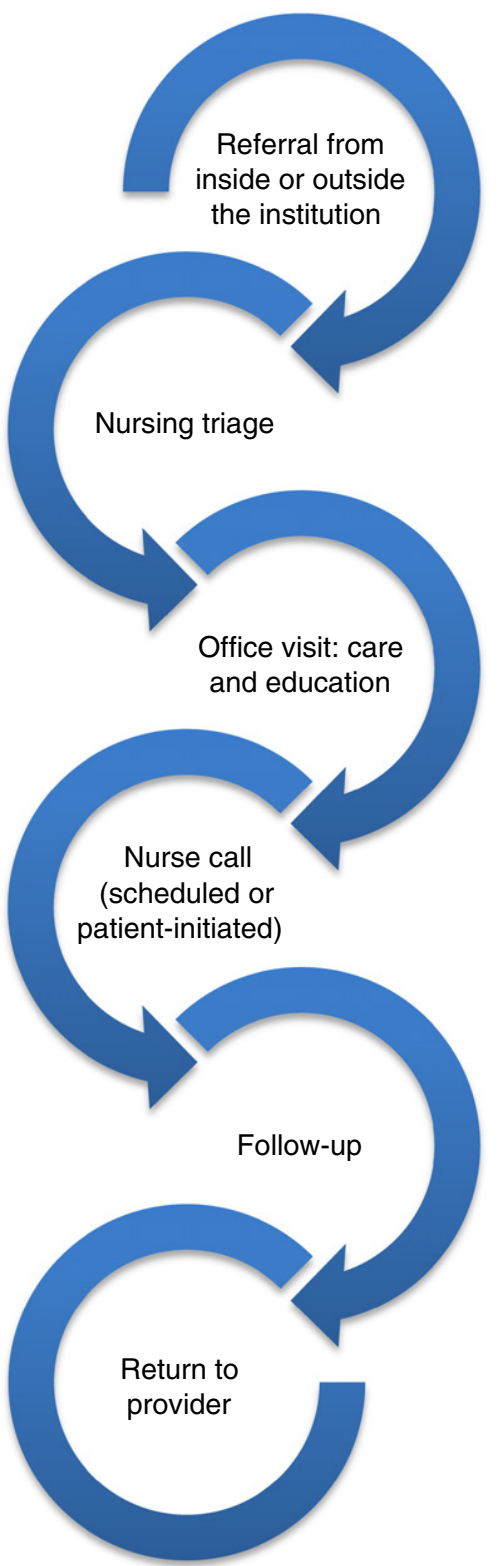

Fig. 1. Flow of patients through the clinic.

to ensure clinic viability and continued success were reviewed. Frequencies were calculated using SPSS version 22.0 (IBM, Amonk, NY, USA) for Windows. No measures of statistical significance were calculated.

\section{Results}

A total of 247 patients were seen over the 4 -year period. The number of new patient visits steadily increased from year 1 to year 4 (Fig. 2). The referral status could be ascertained for 240 (97.2\%) patients. Patient referrals came both from within the UMI Health System (200 patients $[83.3 \%])$ and from other institutions (40 [16.7\%]). Within the UMI Health System, patients were referred from a resident-run practice, the academic generalist group, a certified nurse midwife practice, or the family medicine providers who provided obstetric care. A small number of patients $(2[0.8 \%])$ were self-referrals. The vast majority of patients came from the resident-run practice and the academic generalist group (Fig. 3). The certified nurse midwife practice and the family practice providers accounted for 64 (26.7\%) referrals, even though only approximately $15 \%$ of deliveries in the UMI Health System occurred at these centers.

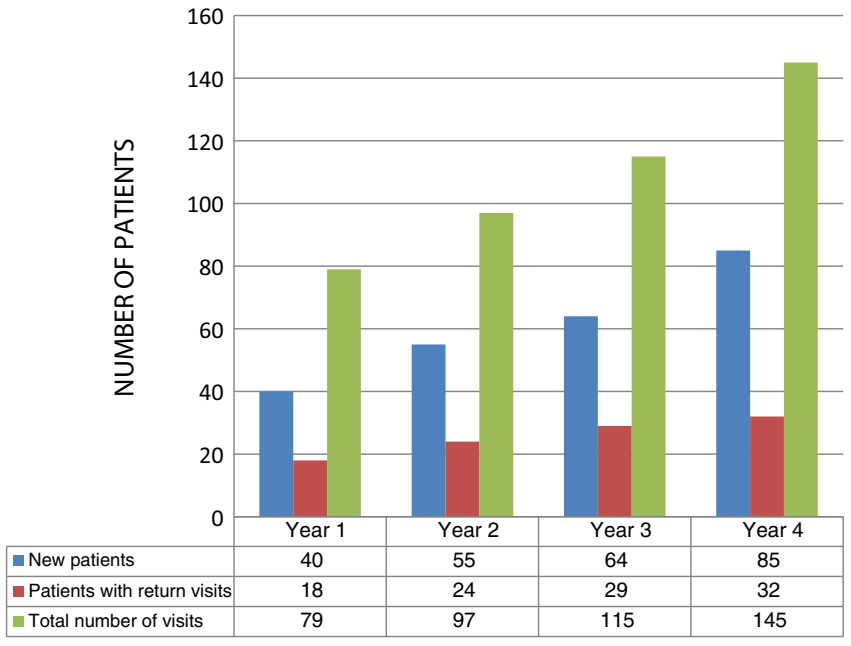

Fig. 2. Number of patient visits by year $(n=247)$.

Patients were referred for various reasons. Most were referred for a postpartum complication such as a poorly healing third- or fourthdegree anal sphincter laceration, incontinence, or persistent pain. If they had delivered outside the system, the team attempted to obtain the records before the visit. A careful history and examination was performed, a care plan formulated that was tailored to the presenting problem, and follow-up scheduled as needed. There was counseling for future deliveries and lifelong pelvic floor health. It was frequently necessary to provide education for the patient on her type of delivery and the extent of her lacerations. Many patients did not know the extent or the type of laceration that had occurred. Few understood the anatomy of the perineum and anal sphincter complex. Detailed drawings and descriptions of perineal trauma and information discussing risks for a subsequent delivery were created for the program and provided appropriately.

The most common primary presenting concerns were third- and fourth-degree lacerations (Table 1). Of the 154 patients who had a third- or fourth-degree laceration, 19 (12.3\%) complained of fecal incontinence at the time of presentation. The primary presenting concern was fecal incontinence for 21 (8.5\%) women. Fecal incontinence was often transient and had resolved by the time of their first visit. More than one complaint at the time of initial visit was recorded in 129 (52.2\%) patients.

Of all patients seen over the 4-year period, 20 (8.1\%) underwent surgery. Of those, six had a rectovaginal fistula repair, five underwent anal sphincteroplasty, five had a perineal/vulvar revision, two had a midurethral sling placed, two had a vaginal prolapse repair, and one

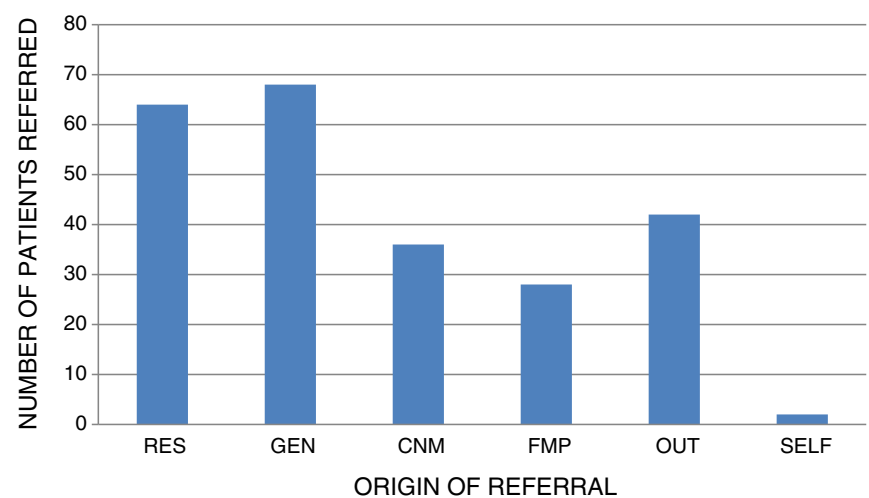

Fig. 3. Referral of patients to the clinic $(n=240)$. Abbreviations: RES, resident/house office clinic practice; GEN, generalist practice; CNM, certified nurse midwife practice; FMP, family medicine practice; OUT, referral from outside the system; SELF, self-referral by patient. 
Table 1

Presenting concerns of patients. ${ }^{\mathrm{a}, \mathrm{b}}$

\begin{tabular}{|c|c|c|c|c|c|c|c|c|}
\hline Year & $\begin{array}{l}\text { Third-degree } \\
\text { laceration }\end{array}$ & $\begin{array}{l}\text { Fourth-degree } \\
\text { laceration }\end{array}$ & $\begin{array}{l}\text { Urinary } \\
\text { incontinence }\end{array}$ & $\begin{array}{l}\text { Pelvic organ } \\
\text { prolapse }\end{array}$ & Pain & $\begin{array}{l}\text { Rectovaginal } \\
\text { fistula }\end{array}$ & $\begin{array}{l}\text { Fecal } \\
\text { incontinence }\end{array}$ & Other \\
\hline Year $1(\mathrm{n}=40)$ & $23(57.5)$ & $6(15.0)$ & $8(20.0)$ & 0 & $2(5.0)$ & $3(7.5)$ & $5(12.5)$ & 0 \\
\hline Year $2(\mathrm{n}=55)$ & $28(50.9)$ & $10(18.2)$ & $4(7.3)$ & $3(5.5)$ & $6(10.9)$ & 0 & $6(10.9)$ & $3(5.5)$ \\
\hline Year $3(n=64)$ & $35(54.7)$ & $7(10.9)$ & $7(10.9)$ & $2(3.1)$ & $11(17.2)$ & $1(1.6)$ & $5(7.8)$ & $4(6.3)$ \\
\hline Year $4(\mathrm{n}=85)$ & $42(47.7)$ & $3(3.4)$ & 14 (15.9) & $6(6.8)$ & $6(6.8)$ & 0 & $5(5.7)$ & $9(10.2)$ \\
\hline Total $(\mathrm{n}=247)$ & $128(51.8)$ & $26(10.5)$ & $33(13.4)$ & $11(4.5)$ & $25(10.1)$ & $4(1.6)$ & $21(8.5)$ & $16(6.5)$ \\
\hline
\end{tabular}

a Values are given as number (percentage).

b Patients might have had more than one presenting concern.

had removal of a Gartner duct cyst. Additionally, office procedures were performed on 33 (13.4\%) patients, including trigger point injections in 11 , suture removal or perineal revision in 11 , removal/cautery of granulation tissue in 10 , and incision and drainage of a perineal abscess in one. Overall, 53 (21.5\%) of the 247 patients required a procedure.

Other common treatments offered included medical treatment for pelvic floor muscle spasm, hemorrhoids, constipation, anal fissures, urinary incontinence, and vaginal atrophy secondary to breastfeeding. A pessary was placed in 17 (6.9\%) patients and vaginal dilator therapy was recommended to $6(2.4 \%)$ patients for levator spasm or perineal pain. An antibiotic or antifungal medication was prescribed for 19 (7.7\%) patients who had an active infection at the time of their initial visit. Thirty-nine (15.8\%) women were referred for pelvic floor physical therapy and most women seen were counseled about pelvic floor exercises and provided with verbal and written instructions.

Each year, less than half the patients initially referred required a follow-up visit (Fig. 2). Once a plan was established, most patients were able to follow up with their primary obstetric provider. Of those who did require a return visit, many were patients who had undergone surgery and required more follow-up care.

\section{Discussion}

The present assessment has shown that a postpartum perineal clinic is a viable clinic modality that offers opportunity for early assessment and treatment of pelvic floor dysfunction. The most common indication for referral was a history of third- or fourth-degree laceration, followed by urinary incontinence and pain. Almost one quarter of the patients seen required a procedure, either in the operating room or office. Pelvic floor physical therapy was recommended for $15 \%$ of the women for management of urinary and fecal incontinence as well as pain. With strong nursing collaboration and communication with referring obstetric providers, the clinic has grown each year and continues to provide specialized care for women with immediate postpartum concerns.

Several challenges were encountered as the present program was established. First, obstetric providers had to be oriented to the services provided. It was stressed that the aim was to improve patient outcomes and postpartum experiences rather than to assess the intrapartum and immediate postpartum care that had been provided. By stressing the positive role of the clinic ("Healthy Healing") and making that the primary mission, any provider challenges could be deferred. Peer-to-peer education was used via Grand Rounds and continuing education conferences to communicate with obstetric providers.

Second, patients needed to be made aware that care was available. Direct-to-patient marketing was implemented via search engines, websites, and accessible patient education materials. Finally, we also worked to raise awareness of our services with the floor nursing staff of the obstetric unit at the UMI Hospital and Health Systems via peerto-peer nursing education. This step was key to the success.

To overcome barriers to patient accessibility, a nurse specialist acted as the single point of entry for all patients, irrespective of whether they were self-referred, inpatients or outpatients within the UMI Health System, or from outside the system. As a result, patients could be seen shortly after delivery. Triage and telephone follow-up were also an important component for the patients' care. Initial nurse triage consisted of assessment of the problem, the time from delivery, and the patient's relevant medical history. If the delivery had occurred at another institution, the process of obtaining outside medical records was initiated. This skilled triage allowed for an efficient first clinic visit and allowed patients to be quickly returned to their providers for further care.

Ease of entry is especially appreciated by patients, who are often overwhelmed in the immediate postpartum period. Having consistent contact with a knowledgeable nurse throughout the entire care cycle was crucial to the success of the present program. Follow-up visits were kept to a minimum, with scheduled phone calls and access to nursing experts. A discrete plan of care could be established at the initial consult visit, with follow-up as needed through the patient's primary obstetric provider.

The patients presented with various symptoms, with most having had a third- or fourth-degree anal sphincter laceration. More than half the women did not know what these terms meant or did not know the extent of their laceration. This finding is consistent with another study [2], in which more than half the women queried could not recall or did not understand the type of laceration or perineal trauma within a few months of delivery.

During the first consultation, all women with known lacerations were given leaflets with pictures and descriptions of their lacerations and explanations of the risks for second delivery, including risk of another sphincter laceration or levator ani injury, and the impact on bowel control. Women who were totally asymptomatic in terms of flatus or fecal incontinence were counseled that they should not elect to have a cesarean delivery. The risk of a second obstetric anal sphincter injury is estimated at 3\%-12\% [3-5]. Women were cautioned that an operative vaginal delivery and/or midline episiotomy could significantly increase the risk of a second sphincter laceration, with the risk being as high as $50 \%[5,6]$.

For women with persistent fecal incontinence with onset at delivery, a complete evaluation and management plan with or without sphincteroplasty was performed. For these women, a cesarean delivery was recommended for their next delivery. The most difficult women to counsel were those with transient incontinence who were asymptomatic at presentation. After evaluation and treatment, this cohort was counseled that their chance of developing permanent incontinence could be as high as $25 \%$ if they sustained another fourthdegree laceration [7-10].

Pain was a common problem for many patients in the program. The etiologies included granulation tissue, skin bridges, infection, and muscle spasm. Genital tract pain is common after vaginal delivery. In one study [11], $38 \%$ of 84 women reported perineal pain 1 week after delivery even with an intact perineum. Several studies $[12,13]$ have shown that episiotomy increases pain to a greater extent than do spontaneous tears and suturing. All patients in the present sample had some degree of perineal laceration. Most were sutured with polyglactic sutures. There were no clear patterns or identifiable causes for poor wound healing or development of granulation tissue.

Presently, there is a limited amount of literature available regarding this type of clinic modality. Fitzpatrick et al. [14] reviewed the 
experience at a clinic in Dublin, Ireland. There, clinicians assessed not only women with postpartum problems but also those aged 18-77 years who had anal incontinence. A total of 185 patients were seen at that clinic in its first year. Pretlove et al. [15] reported on the experience at in a UK clinic, which was limited to women with a primary obstetric anal sphincter injury and anal incontinence related to childbirth, which is probably representative of the clinics presently running in Europe. In the first 18 months of operation, the clinic saw 55 patients [15], not inconsistent with the experience at the Michigan Healthy Healing After Delivery Clinic.

Many studies $[16,17]$ have focused on the long-term impact of birth trauma on the pelvic floor as it relates to pelvic organ prolapse and urinary incontinence. However, less attention has been paid to the immediate postpartum concerns of women following vaginal delivery. A few studies $[18,19]$ have shown the impact of birth and birth trauma on short-term function, including fecal incontinence, urinary incontinence, perineal pain, and sexual function. In the present cohort, $21.5 \%$ of patients assessed required some type of procedure. Many were minor office modifications of a poorly healing laceration, but $8.1 \%$ required surgery. With one in five patients requiring active intervention, the need for this type of specialized care is clearly warranted. Consequently, data collection at the Michigan Healthy Healing After Delivery Clinic will be continued for translational research efforts. The patient experience is being assessed and the value of early intervention for postpartum consequences of complex vaginal births is being determined.

Now in its sixth year, the Michigan Healthy Healing After Delivery Clinic has attained viability by a collaborative, not competitive, model of care. Referrals from non-obstetrics/gynecology providers, outside providers, and patients themselves have been promoted, with timely consultations and effective communication. The clinic has moved beyond viability to translational research and protocol development. It is hoped that this model of care can be adopted by other centers to improve peripartum care and reduce the morbidity of untreated perineal trauma.

\section{Conflict of interest}

The authors have no conflicts of interest.

\section{References}

[1] Thakar R, Sultan AH. Postpartum Problems and the Role of a Perineal Clinical. In: Sultan AH, Thakar R, Fenner DE, editors. Perineal and Anal Sphincter Trauma: Diagnosis and Clinical Management. London: Springer; 2007. p. 65-79.

[2] Elkadry E, Kenton K, White P, Creech S, Brubaker L. Do mothers remember key events during labor? Am J Obstet Gynecol 2003;189(1):195-200.

[3] Basham E, Stock L, Lewicky-Gaupp C, Mitchell C, Gossett DR. Subsequent pregnancy outcomes after obstetric anal sphincter injuries (OASIS). Female Pelvic Med Reconstr Surg 2013;19(6):328-32.

[4] Baghestan E, Irgens LM, Bordahl PE, Rasmussen S. Risk of recurrence and subsequent delivery after obstetric anal sphincter injuries. BJOG 2012;119(1):62-9.

[5] Peleg D, Kennedy CM, Merrill D, Zlatnik FJ. Risk of repetition of a severe perineal laceration. Obstet Gynecol 1999;93(6):1021-4.

[6] Payne TN, Carey JC, Rayburn WF. Prior third- or fourth-degree perineal tears and recurrence risks. Int J Gynecol Obstet 1999;64(1):55-7.

[7] Sangalli MR, Floris L, Faltin D, Weil A. Anal incontinence in women with third or fourth degree perineal tears and subsequent vaginal deliveries. Aust N Z J Obstet Gynaecol 2000;40(3):244-8.

[8] Fynes M, Donnelly V, Behan M, O'Connell PR, O'Herlihy C. Effect of second vaginal delivery on anorectal physiology and faecal continence: a prospective study. Lancet 1999;354(9183):983-6.

[9] Donnelly V, Fynes M, Campbell D, Johnson H, O'Connell PR, O'Herlihy C. Obstetric events leading to anal sphincter damage. Obstet Gynecol 1998;92(6):955-61.

[10] Tetzschner T, Sørensen M, Lose G, Christiansen J. Anal and urinary incontinence in women with obstetric anal sphincter rupture. Br J Obstet Gynaecol 1996;103(10): 1034-40.

[11] Macarthur AJ, Macarthur C. Incidence, severity, and determinants of perineal pain after vaginal delivery: a prospective cohort study. Am J Obstet Gynecol 2004; 191(4):1199-204.

[12] Klein MC, Gauthier RJ, Robbins JM, Kaczorowski J, Jorgensen SH, Franco ED, et al. Relationship of episiotomy to perineal trauma and morbidity, sexual dysfunction, and pelvic floor relaxation. Am J Obstet Gynecol 1994;171(3):591-8.

[13] Gordon B, Mackrodt C, Fern E, Truesdale A, Ayers S, Grant A. The Ipswich Childbirth Study: 1. A randomised evaluation of two stage postpartum perineal repair leaving the skin unsutured. Br J Obstet Gynaecol 1998;105(4):435-40.

[14] Fitzpatrick M, Cassidy M, O'Connell PR, O'Herlihy C. Experience with an obstetric perineal clinic. Eur J Obstet Gynecol Reprod Biol 2002;100(2):199-203.

[15] Pretlove S, Thompson PJ, Toozs-Hobson PM, Radley S. The first 18 months of a new perineal trauma clinic. J Obstet Gynaecol 2004;24(4):399-402.

[16] DeLancey JO, Kearney R, Chou Q, Speights S, Binno S. The appearance of levator ani muscle abnormalities in magnetic resonance images after vaginal delivery. Obstet Gynecol 2003;101(1):46-53.

[17] Kearney R, Miller JM, Ashton-Miller JA, DeLancey JO. Obstetric factors associated with levator ani muscle injury after vaginal birth. Obstet Gynecol 2006:107(1):144-9.

[18] Rogers RG, Leeman LM, Migliaccio L, Albers LL. Does the severity of spontaneous genital tract trauma affect postpartum pelvic floor function? Int Urogynecol J Pelvic Floor Dysfunct 2008;19(3):429-35.

[19] Leeman LM, Rogers RG. Sex after childbirth: postpartum sexual function. Obstet Gynecol 2012;119(3):647-55. 